\title{
Study the Effect of Milling Parameters on HE-MA Nanostructured Al-Graphene Cermet Particles
}

\author{
Jagannadh V.S.N. Sripada *, Megil F. Gallant and Gobinda C. Saha * \\ Nanocomposites and Mechanics Laboratory, University of New Brunswick, Fredericton, NB E3B 5A3, \\ Canada; mgallan7@unb.ca \\ * Correspondence: jsripada@unb.ca (J.V.S.N.S.); gsaha@unb.ca (G.C.S.); Tel.: +1-506-458-7784 (G.C.S.)
}

Received: 15 February 2019; Accepted: 10 March 2019; Published: 14 March 2019

\begin{abstract}
Nanocrystalline grains have proven to be excellent reinforcing elements in nanostructured particulate materials. On the other hand, carbon allotropes, especially graphene and carbon nanotube (CNT), exhibit elastic modulus in the range of $1 \mathrm{TPa}$ (theoretical) and tensile strength in multiple orders greater than that of steel. This study aims at synthesizing high-strength nanostructured ceramic-metallic (cermet) particle feedstock in a high-energy mechanical alloying (HE-MA) process based on an Al-graphene composite comprehensive design-of-experiments (DoE). The goal is to optimize milling process parameters, including milling time, batch composition, ballto-power (BPR) ratio, and milling agent, for the particles to be eventually fed into a high-pressure cold spray coatings development. The milled powders are characterized using SEM, EDS, XRD, and laser particle diffractometer to study the morphology and microstructure, elemental composition, grain size and crystal orientation, and particle size distribution (PSD), respectively. Results show it was possible to attain required structure and PSD at a 10:1 BPR with 5-mm diameter ball, at 1200 $\mathrm{rpm}$, and $4 \mathrm{~h}$ of milling.
\end{abstract}

Keywords: Al-graphene nanocomposite; high-energy mechanical alloying; microstructure characterization

\section{Introduction}

It is very common in aerospace and automotive industries to seek lightweight materials, such as aluminum, when designing and building vehicles. This is due to the advantageous properties of aluminum, being lightweight and abundant on earth, however, aluminum has its limitations in areas such as strength, as well as wear and corrosion resistance. To compensate for corrosion, often an alloyed version-AA6061, is used due to its exceptional corrosion resistance. To enhance the hardness, strength and wear resistance of AA6061, it is desired to create a nanocomposite material with a combination of the AA6061 alloy and graphene. Graphene, which exhibits exceptional properties such as strength, is also a very lightweight carbon-based material. When these two materials are combined to create a nanostructured material that can be used as feedstock in the coatings process onto substrates in order to protect them from corrosion, increase strength and hardness, and decrease overall component weight in comparison with standard coatings is a novel idea. The process by which the substrate will be sprayed is the high-pressure cold spray (HPCS), where feedstock is propelled through a high-speed deLaval converging-diverging nozzle. The feedstock, being the AA6061-graphene nanocomposite will be created using high-energy mechanical alloying (HE-MA), where powdered samples are created through ball milling.

Aluminum is the third most abundant element found in the earth-after oxygen and silicon. It is known for its lightweight, low density, machinability, and corrosion resistance by forming a passive layer of $\mathrm{Al} 2 \mathrm{O} 3$ on its surface. In industry, aluminum is often alloyed with other elements 
such as $\mathrm{Cu}, \mathrm{Mg}, \mathrm{Si}, \mathrm{Zn}$, to achieve desired properties. Note that $70 \%$ of commercial civil aircraft airframes are made from $\mathrm{Al}$ alloys [1], emphasizing its role in a variety of applications. These properties, combined with its economic viability, makes $\mathrm{Al}$ one of the most sought-after materials known. However, with the development and growth in materials science, researchers have found the necessity to improve certain properties of aluminum and its alloys to further improve its mechanical properties and make it more applicable in other areas [2].

Allotropes of Carbon, such as Graphene, Fullerenes, Carbon nanotubes (CNT) have all been discovered in recent decades. Their use and prominence have been realized in various fields due to their superior mechanical properties with weight reduction performances-thus giving them the potential to serve as exceptional reinforcement materials. For the purposes of this investigation, graphene is only of interest. It has been known to possess tremendous properties, including a theoretical Young's Modulus of $1 \mathrm{TPa}$, a tensile strength in the range of $130 \mathrm{GPa}$, theoretical specific surface area of $2630 \mathrm{~m}^{2} \mathrm{~g}^{-1}$, thermal conductivity of $5000 \mathrm{~W} \mathrm{~m}^{-1} \mathrm{~K}^{-1}$ and a density of $0.16 \mathrm{mg} / \mathrm{m}^{3}[3,4]$. Clearly these properties make it an ideal reinforcement in composites. It should be noted that graphene is also known to have a great ability to distribute force from an impact, having a force transmission speed of $22.2 \mathrm{~km} / \mathrm{s}$.

Since Graphene was only isolated for the first time in 2004, research on graphene is still in its early stages, with majority of its use being found in biological engineering and optoelectronics because of its large surface area and exceptional electronic and optical properties. Also, compared to other carbon allotropes like CNT and carbon fiber, it is much lighter and possess higher stiffness and strength, comparatively. While the lightweight alloys are promising for weight reduction, ductility, and strength, the carbon based nano materials reinforced composites can offer superior mechanical properties with weight reduction performance. At the same time, AA6061 alloy is commonly used in transportation industries due to competitive mechanical properties and superior corrosion resistance. These exciting properties have led to the decision to test graphene as a reinforcement material in AA6061 alloy, which is expected to lead to a reinforced nano-composite material which possesses improved mechanical properties and corrosion resistance. This nano-composite could then be used in CS coating applications to increase strength and prevent corrosion of base materials in desired parts.

Cold Spray technology has been gaining enormous traction among researchers for of its ability to deposit coatings without high temperature requirements and also due to its faster and more effective deposition capabilities. Dense, nonporous structures, good adhesion, adequate thickness and no oxidation or phase transformations are some of the advantages of cold spray. This cold spray technology had been developed in 1980's at the Institute of theoretical and applied mechanics in the Siberian division of Russian Academy of Science in Novosibirsk [5,6]. When the flow particles are accelerated on a target surface above a certain critical velocity, they have observed a transition from erosion of particles on the target surface to adherence of the flow particles themselves on the target surface. Cold Spray deposition process involves accelerating feedstock through a converging- diverging nozzle at supersonic velocities, generally measured in Mach. The particles undergo severe plastic deformation upon impact and adhere to the surface. The high deformation associated with power particles results in conformal contact with the substrate surface under a very high localized pressure, resulting in high bond strength. To achieve critical particle velocities, feed stock powder particles are introduced into supersonic gas flow. Since severe plastic deformation is associated with the process, cold spray is initially limited to ductile materials. However, researchers have attempted cold spray process with metal matrix ceramic composites [7-11]. It is also proven by these researchers that ceramics aid the cold spray by promoting deformation of metal phase and improves coating density and hardness.

There are two types of cold spray available in literature. High pressure cold spray and low pressure cold spray. In High pressure cold spraying (HPCS), powder is fed axially to the gas flow, whereas in low pressure (LPCS), powder is fed radially to the gas flow or perpendicular to the diverging part of the nozzle. HPCS utilizes gases such as $\mathrm{N}_{2}$ and $\mathrm{He}$, whereas compressed air is used in case of LPCS. Pressures in the range of 7-40 bar are used in HPCS whereas LPCS utilizes 
pressure in the range of 6-10 bar. The advantages of HPCS over LPCS are larger materials selection and higher quality of deposits, however, LPCS is a much cheaper process and has higher portability for equipment. Moreover, powder feed rates are greater in HPCS but particle concentration in gas flow can be higher in LPCS.

Since cold spray is a solid-state process, powder particles are fed into the supersonic gas flow to achieve critical particle velocity required for adhesion on impact. When a supersonic flow is impacted onto the substrate, the supersonic gas velocity is instantly reduced to very low velocity and increases pressure and temperature locally [12]. This change is visualized as a shock wave. Gas velocity decreases along the shock wave to zero at the substrate surface. And hence the particle velocity will be at a lower value compared to the value it had when it exited the spray nozzle. For cold spray to succeed, a critical size range of the particles is required, this is important when developing the feedstock material. Even though smaller particles achieve higher acceleration in the flow stream, they also decelerate rapidly in the shock wave zone. As the particle size increases, velocity of the particle at the nozzle exit decreases but they maintain the velocity past the shock wave. However if the particle sizes are very high, the velocity will be too low for sufficient impact and bonding. Hence a required particle size range exists for cold spray to have effective coating characteristics, normally in the range of 10 to $100 \mu \mathrm{m}$ for nanomaterials [13].

HE-MA process is solid state powder processing technique in which powder mixtures placed in a ball mill are subjected to high energy collision from the impact of balls, resulting in repeated cold welding, fracturing and re-welding of the particles. This is one of the most simple and effective ways to achieve homogeneous dispersion of graphene inside aluminum matrix and have been successfully used by various other authors [14-20]. This same method will be used to develop feedstock for the cold-spray process. In the HE-MA process, the relatively ductile AA6061 alloy undergoes continuous plastic deformation, fracturing and re welding during which the finer graphene particles are embedded into the ductile AA6061 alloy. HE-MA process involves loading the powders into a steel vial containing balls and milling them in a high energy ball mill. The main parameters involved in this milling process are ball to powder ratio, duration of milling time, diameter of the balls and the composition of the powder specimens that are extrinsic to the mill. By varying these milling parameters, nature and quality of the feedstock can be varied. The objective of this study is to analyze the effect of milling parameters on the effective particle size distribution of AA6061-graphene nano-composites synthesized by high energy mechanical alloying.

\section{Materials and Methods}

\subsection{Powder Samples Preparation}

Matrix and reinforcement powders, 6061-aluminum and graphene, were obtained from the manufacturers Supersonic Spray Technologies (LaSalle, ON, Canada) and Sky Spring Nano materials Inc. (Houston, TX, USA), respectively. For this experiment three main parameters are investigated; ball-to-powder ratio (BPR); ball diameter; and duration of time for each milling operation. For this experiment, two BPRs of 5:1 and 10:1 [21] and hardened-steel balls with diameters of $5 \mathrm{~mm}$ and $10 \mathrm{~mm}$ are chosen based on the available literature. As for the milling time, samples were to be milled for 1,2 and $4 \mathrm{~h}$ intervals. This period is based on practical milling times for industry standards, as it is not efficient to mill single samples for significant periods of time. Parameters such as batch size and composition were fixed at a total of $10 \mathrm{~g}$ and composition consisting of $99 \%$ aluminum and $1 \%$ graphene. It should be noted that a processcontrol-agent was added to the powder to prevent agglomeration. An amount of 1.5 wt \% of stearic-acid was added to the powder.

Table 1 highlights the three main parameters of the 12 samples investigated in this experiment. For simplicity sake, the authors would like to advise that all numbers of the form $3 n(n=1,2$, 
$3,4)$ corresponds to samples milled for $4 \mathrm{~h}, 3 n+1(n=0,1,2,3)$ corresponds to samples milled for $1 \mathrm{~h}$ and $3 n+2(n=0,1,2,3)$ corresponds to samples milled for $2 \mathrm{~h}$.

Table 1. Nomenclature and parameters of milled samples .

\begin{tabular}{cccc}
\hline Sample & Ball-to-Power $(\mathbf{g} / \mathbf{g})$ & Ball Diameter $(\mathbf{m m})$ & Time $(\mathbf{h})$ \\
\hline 1 & $5: 1$ & 10 & 1 \\
2 & $5: 1$ & 10 & 2 \\
3 & $5: 1$ & 10 & 4 \\
4 & $10: 1$ & 10 & 1 \\
5 & $10: 1$ & 10 & 2 \\
6 & $10: 1$ & 10 & 4 \\
7 & $5: 1$ & 5 & 1 \\
8 & $5: 1$ & 5 & 2 \\
9 & $5: 1$ & 5 & 4 \\
10 & $10: 1$ & 5 & 1 \\
11 & $10: 1$ & 5 & 2 \\
12 & $10: 1$ & 5 & 4 \\
\hline
\end{tabular}

Before milling began, all preparations were done within an argon-atmosphere to prevent reaction with surroundings. Samples were weighed, mixed and enclosed inside steel-vials along with appropriate balls in this atmosphere. Powder mixtures were then milled in a Spex-8000m mechanical mill (SPEX SamplePrep, Metuchen, NJ, USA), at approximately $1000 \mathrm{rpm}$. Samples 1-3 were all collected from the same powder-mixtures as they had consistent parameters other than time. Milling operations were interrupted every half-hour for $10 \mathrm{~min}$ to allow cooling within the system, and small powder-samples were removed from the vials in argon atmosphere at the 1- and 2-h marks, with the remainder taken at the final 4-h mark (to maintain effective BPR, ball/s weighing equivalently to the removed powder weight are simultaneously removed). The same procedure was followed for Samples 4-6, 7-9 and 10-12.

\subsection{Material Characterization}

Once milling was completed, samples were placed in an argon-filled furnace at $420{ }^{\circ} \mathrm{C}$ to eliminate stearic acid within samples. Portions of powder were then cold-mounted using epoxy and hardener, and polished upon hardening in order to be analyzed using scanning-electron microscopy (SEM). Polishing was carried out using grit sizes of 400, 800 and 1200 grit, followed by a $0.1 \mu \mathrm{m}$ diamond polish and finally colloidal silica polish. Further analyses such as X-ray diffraction (XRD) was done in order to determine composition and phases of the mixture, and the laser diffraction method was used in a Malvern particle size analyzer (Model Mastersizer MAZ2000S, Malvern Instruments, Malvern, UK) in order to determine particle sizes of milled products. Particle size distribution of the powder samples is measured using Malvern particle analyzer. Malvern particle analyzer uses laser diffraction technique to generate a volume distribution for the analyzed data. Before powder specimens (mixed with dispersant) are placed inside the analyzer, background noise is calculated. The background noise is subtracted from the analyzed data to give the particle size distribution of the powder particles. Particle size distribution data is calculated 3 times for each sample and then averaged. The image below represents the SEM image of the asreceived Al-6061 to serve for futurecomparisons.

Materials and Methods should be described with sufficient details to allow others to replicate and build on published results. Please note that publication of your manuscript implicates that you must make all materials, data, computer code, and protocols associated with the publication available to readers. Please disclose at the submission stage any restrictions on the availability of materials or information. New methods and protocols should be described in detail while well-established methods can be briefly described and appropriately cited.

Research manuscripts reporting large datasets that are deposited in a publicly available database should specify where the data have been deposited and provide the relevant accession numbers. If 
the accession numbers have not yet been obtained at the time of submission, please state that they will be provided during review. They must be provided prior to publication.

Interventionary studies involving animals or humans, and other studies require ethical approval must list the authority that provided approval and the corresponding ethical approval code.

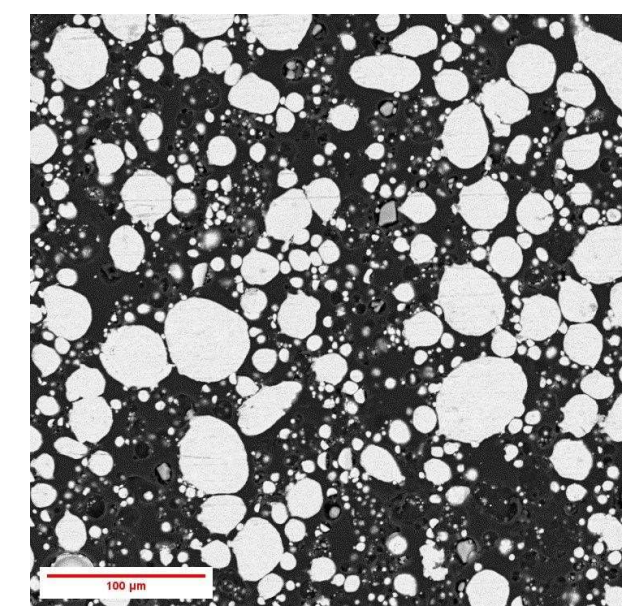

Figure 1. SEM micrograph of as-received AA6061.

\section{Results}

Table 2 serves to highlight the composition of the AA6061 alloy as it was received and before mixing.

Table 2. Composition of the as-received AA6061 alloy.

\begin{tabular}{ccccccccc}
\hline $\mathbf{S i}$ & $\mathbf{M g}$ & $\mathbf{C u}$ & $\mathbf{F e}$ & $\mathbf{C r}$ & $\mathbf{Z n}$ & $\mathbf{T i}$ & $\mathbf{M n}$ & $\mathbf{A l}$ \\
\hline $0.4-0.8 \mathrm{wt} \%$ & $0.8-1.2 \mathrm{wt} \%$ & $0.15-4 \mathrm{wt} \%$ & $0.7 \mathrm{wt} \%$ & $0.35 \mathrm{wt} \%$ & $0.25 \mathrm{wt} \%$ & $0.15 \mathrm{wt} \%$ & $0.15 \mathrm{wt} \%$ & remainder \\
\hline
\end{tabular}

\subsection{Scanning Electron Microscopy}

Microstructure and morphology of the powder samples are observed using JEOL 6400 Scanning Electron Microscope (SEM, JEOL, Tokyo, Japan) using Secondary Electron (SE) mode and Backscattered Electron/comp (BSE) mode. All the polished samples are carbon coated before mounting onto the microscope. This is necessary to create conductive layer on the surface of the sample and thus improve imaging and prevent charging of electrons. Figure 1 is the microstructure of the as received AA6061 alloy. The particles are spherical in shape. However Figure 2a-j represents the microstructures of powdered alloys under different milling conditions. Figure $2 \mathrm{a}, \mathrm{d}, \mathrm{f}, \mathrm{h}$ correspond to microstructures of the powders after $1 \mathrm{~h}$ of milling. It can be observed that the particles have formed flaky morphology and have agglomerated. It can be inferred that at the beginning of HE-MA, two simultaneous events have occurred. The powders begin to intimately mix and the balls have started to flatten the powders. The flaky morphology can be attributed to flattening of powders by balls and increase in particle size distribution observed in Table 3 is the result of agglomeration of powder particles. HE-MA process is characterized by plastic deformation, fracture and cold welding. The force of impact caused by collision of balls plastically deform and fracture the relatively ductile phase of the composite, being AA6061. Subsequent cold welding occurs when two of these fractured, clean surfaces come into contact with each other. Agglomerations observed after $1 \mathrm{~h}$ of milling in all the powder samples can be explained by this phenomenon. At this stage this microstructure have no significant value but this flattening facilitates dispersion of reinforcement phase (Graphene in this case) into matrix phase (AA6061) by providing more sites for embedment [22].

Figure $2 \mathrm{~b}, \mathrm{i}$ corresponds to powders after $2 \mathrm{~h}$ of milling. It is observed that the initial flakes have disappeared and the particles of varying sizes, ranging from huge chunks $(>100 \mu \mathrm{m})$ to finer particles, are present. There is no definite shape associated with particles, meaning the particles are 
heterogeneous with varying shapes and size. This is an intermediate stage of the milling where both cold welding and fracturing are dominant processes.

Figure $2 \mathrm{c}, \mathrm{e}, \mathrm{g}, \mathrm{j}$ is the microstructures of powders after $4 \mathrm{~h}$ of milling. In general, all four microstructures appear to have homogeneous structure with particles consisting of polygonal and near spherical structures. This is a positive aspect in terms of cold spraying. Especially in Figure $2 \mathrm{j}$ which depicts a very homogeneous structure with a favorable particle distribution (see Table 3). The corresponding milling parameters for Figure $2 j$ are 10:1 for BPR with $5 \mathrm{~mm}$ diameter balls.
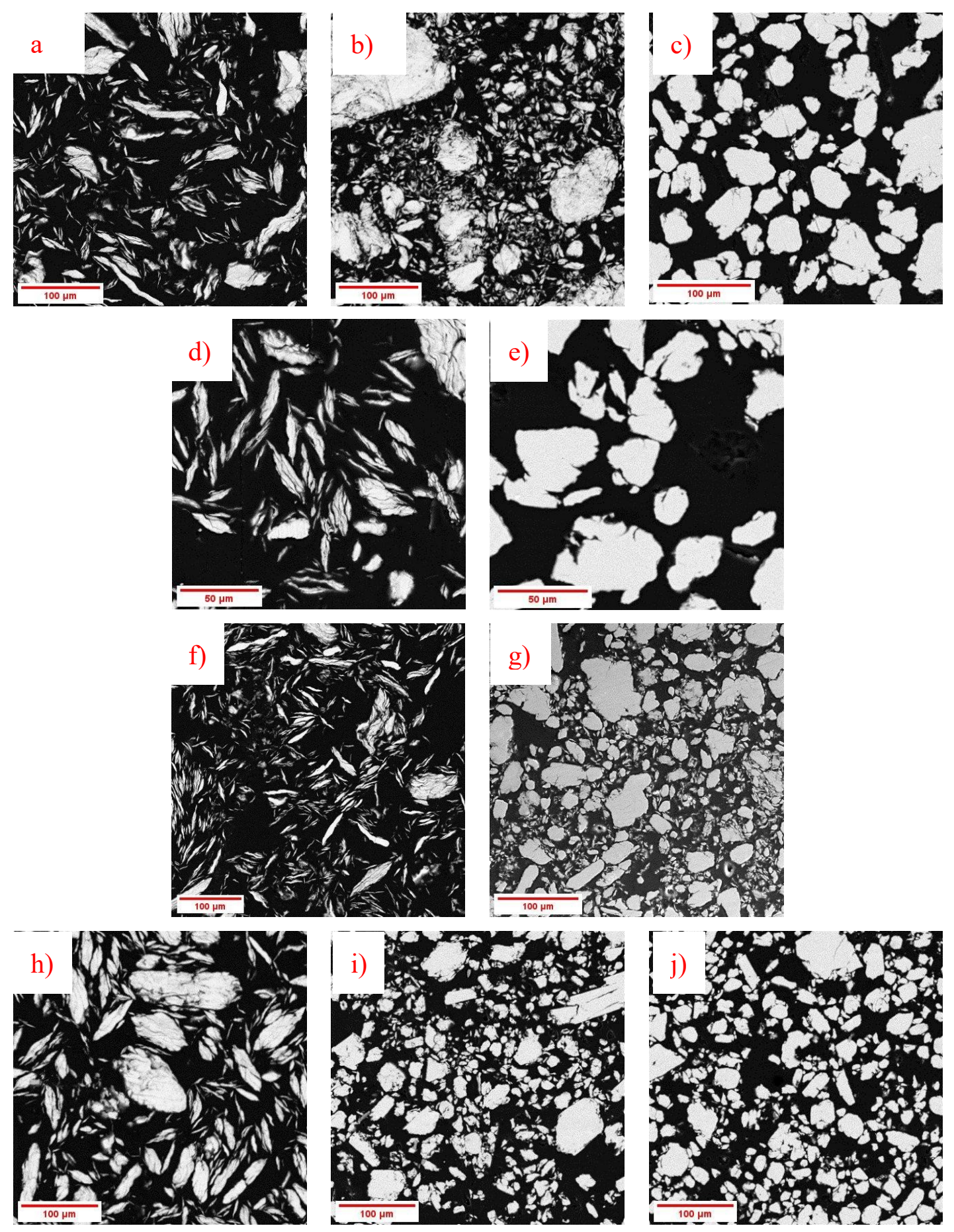

Figure 2. SEM images of showing particles of milled powder with mill parameters: (a) $10 \mathrm{~mm}$ ball, 5:1 BPR at $1 \mathrm{~h}$; (b) $10 \mathrm{~mm}$ ball, 5:1 BPR at 2; (c) $10 \mathrm{~mm}$ ball, 5:1 BPR at 4 h; (d) $10 \mathrm{~mm}$ ball, 10:1 BPR at $1 \mathrm{~h}$; (e) $10 \mathrm{~mm}$ ball, 10:1 BPR at $4 \mathrm{~h}$; (f) $5 \mathrm{~mm}$ ball, 5:1 BPR at $1 \mathrm{~h}$; (g) $5 \mathrm{~mm}$ ball, 5:1 BPR at $2 \mathrm{~h}$; (h) 5 $\mathrm{mm}$ ball, 10:1 BPR at $1 \mathrm{~h}$; (i) $5 \mathrm{~mm}$ ball, 10:1 BPR at $2 \mathrm{~h}$; (j) $5 \mathrm{~mm}$ ball, 10:1 BPR at $4 \mathrm{~h}$. 
Table 3. Mean particle size distribution of all the alloyed samples and as received AA6061 alloy.

\begin{tabular}{ccccccc}
\hline Sample & $\boldsymbol{d}_{0.1}(\boldsymbol{\mu m})$ & $\boldsymbol{d}_{0.5}(\boldsymbol{\mu m})$ & $\boldsymbol{d}_{0.9}(\boldsymbol{\mu m})$ & Time $(\mathbf{h})$ & ball Diameter $(\mathbf{m m})$ & BPR \\
\hline 1 & 14.079 & 48.731 & 191.697 & 1 & 10 & $5: 1$ \\
2 & 7.746 & 35.363 & 196.35 & 2 & 10 & $5: 1$ \\
3 & 25.164 & 82.879 & 360.869 & 4 & 10 & $5: 1$ \\
4 & 15.099 & 49.141 & 200.171 & 1 & 10 & $10: 1$ \\
5 & 18.557 & 62.745 & 214.701 & 2 & 10 & $10: 1$ \\
6 & 22.940 & 56.004 & 149.433 & 4 & 10 & $10: 1$ \\
7 & 13.283 & 38.577 & 154.461 & 1 & 5 & $5: 1$ \\
8 & 8.932 & 26.202 & 100.57 & 2 & 5 & $5: 1$ \\
9 & 6.582 & 27.03 & 106.885 & 4 & 5 & $5: 1$ \\
10 & 16.300 & 45.315 & 146.077 & 1 & 5 & $10: 1$ \\
11 & 7.261 & 19.352 & 53.953 & 2 & 5 & $10: 1$ \\
12 & 12.034 & 30.776 & 85.954 & 4 & 5 & $10: 1$ \\
$\mathrm{Al}$ & 7.831 & 22.146 & 48.014 & - & - & - \\
\hline
\end{tabular}

\subsection{X-ray Diffraction Measurements}

This AA6061 alloy also has Si etc. compositions with $<1 \%$, but no traces of the alloying elements as well as reinforcing component are detected in XRD (Figure 3). This could be attributed to the equipment detectability, a minimum of $1 \mathrm{wt} \%$ of compositional elements are required by this XRD. Future changes in the batch composition will be carried forward.

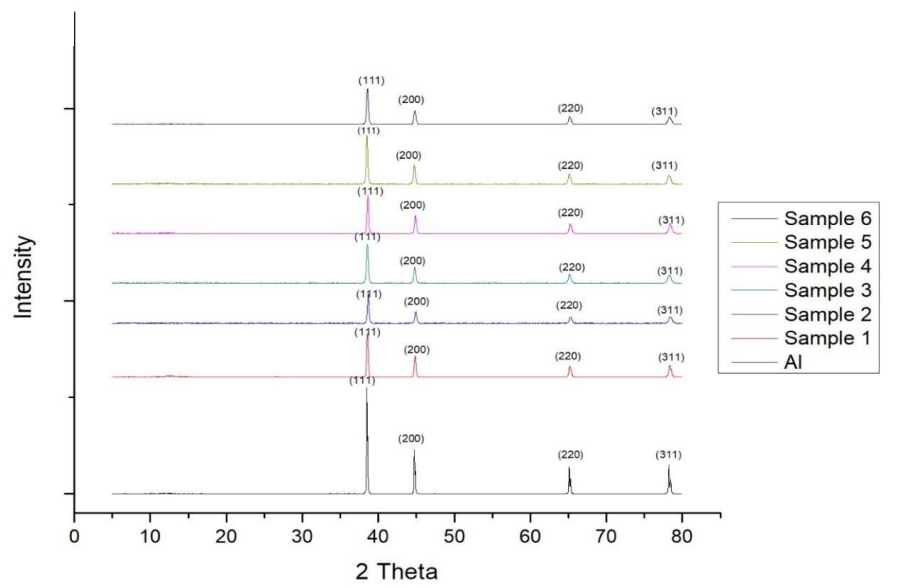

(a)

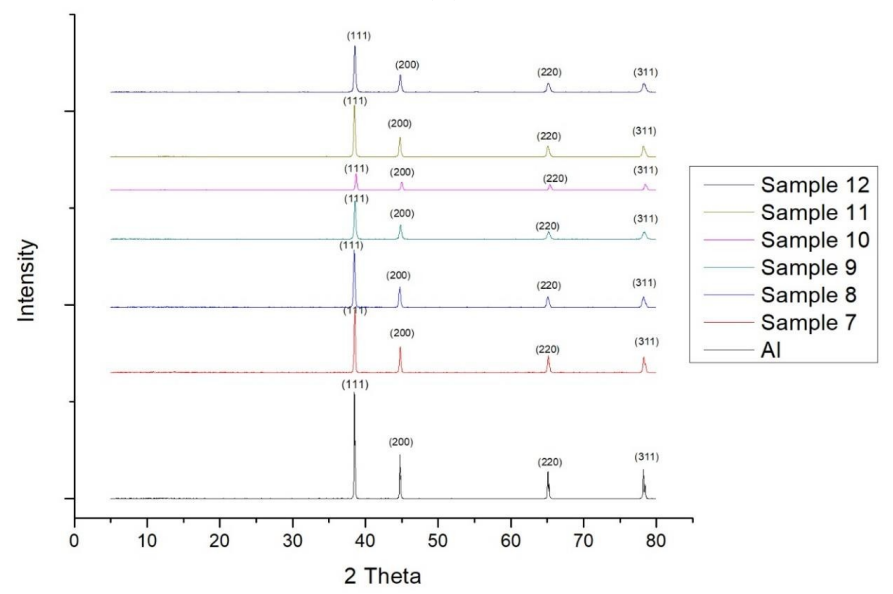

(b)

Figure 3. XRD analysis of the synthesized particles for (a) Samples 1-6 and (b) Samples 7-12 compared with AA6061. 


\subsection{Particle Size Distribution}

The plots of average and the individual calculations are examined simultaneously to verify the accuracy and observe any deviations are present. All the plots of calculated and mean values of the powder samples have perfectly overlapped with each other confirming no deviations were present in the calculated values. Plots of Samples 1, 5, 7, 12 are presented in the Figure 4. The average values are presented in Table 3.
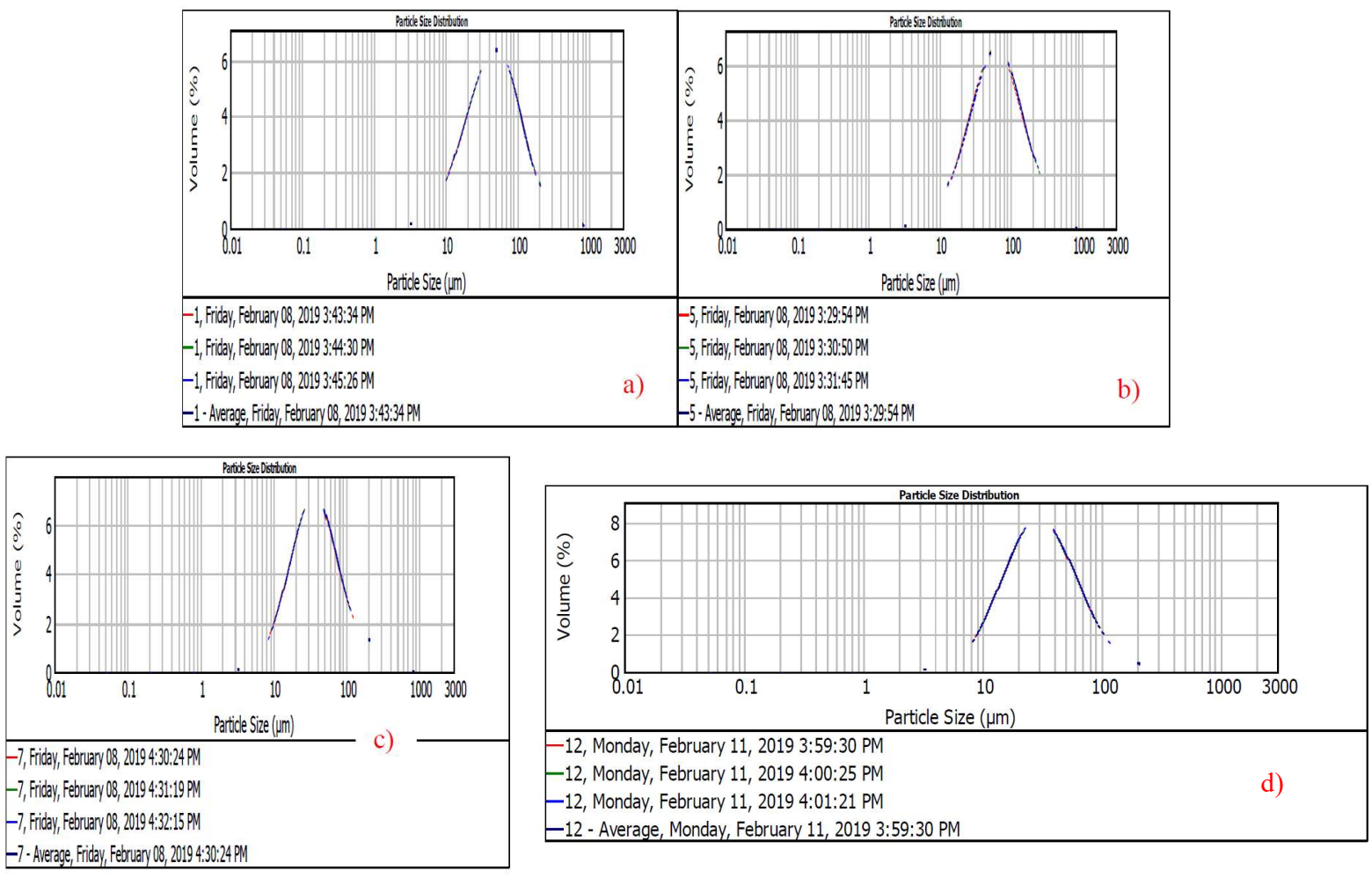

Figure 4. Particle size distribution of (a) Sample 1, (b) Sample 5, (c) Sample 7, and (d) Sample12.

From Figure 4, it is clear that there are no deviations of values and all the curves are perfectly overlapping with the mean value (and each other). Also it can be seen that the maximum area of the curve for the Sample 12 (5 mm ball diameter, 10:1 BPR, $4 \mathrm{~h}$ milling) lies in the range of 10-100 $\mu \mathrm{m}$ which is the desired particle size distribution range for cold spray to obtain effective coating characteristics [13].

From Table 3, particle size values corresponding to $d_{0.1}, d_{0.5}, d_{0.9}$ represent the percentiles of the volume percentage of the particles. The value corresponding to $d_{0.1}$ represents the size of particle for which 10 vol.\% of the sample is comprised of particles less than this size. As for $d_{0.5}$, this represents the size of particle at which 50 vol.\% of the particles are less and 50 vol.\% are greater than the corresponding size. The value corresponding to $d_{0.9}$ represents the size of particle for which 90 vol.\% of the particles are lesser than this size.

Subsequent findings of the particle size distribution are discussed in regard with varying parameters as shown in the following sections.

\subsubsection{Effect of Time on Particle Size Distribution}

Figure $5 \mathrm{a}-\mathrm{d}$ corresponds to powder samples after $1 \mathrm{~h}$ of milling under different milling conditions. From Table 3, it is clearly observed that the particle size distribution of the as-received alloy is narrow and in the range of less than $50 \mu \mathrm{m}$. After $1 \mathrm{~h}$ of milling the particle size distribution for all the samples appear to have significantly increased. This can be attributed to the aforementioned agglomerations

From Table 3 and Figure 5, it is inferred that milling initially is dominated by cold welding- 
evident by the increase in the overall particle size distribution of all specimens, irrespective of their parameters.

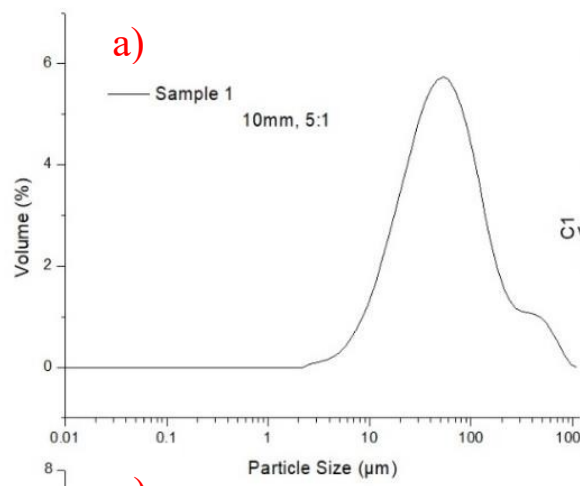

b)
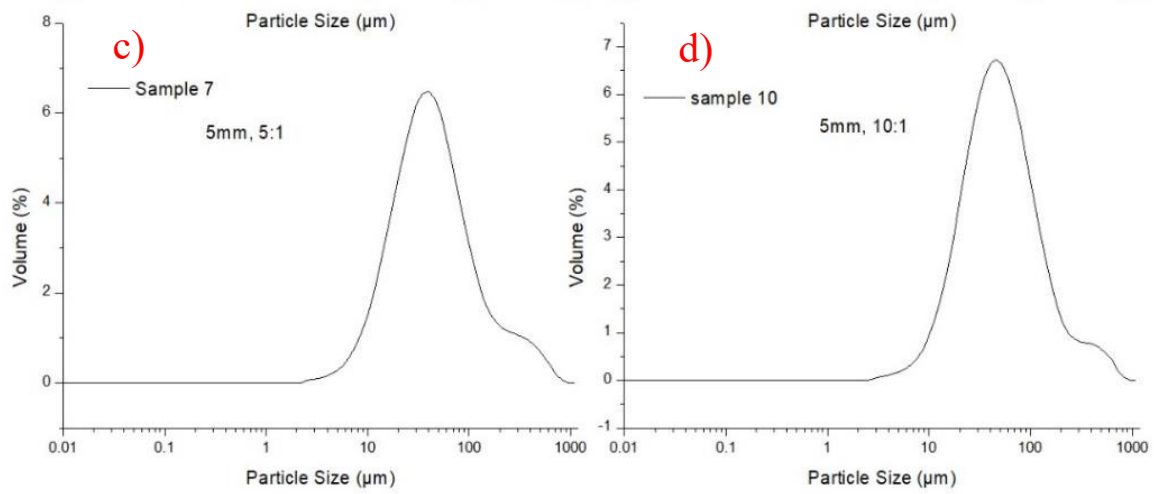

Figure 5. Evolution of PSD at $t=1 \mathrm{~h}$ for (a) Sample 1, (b) Sample 4, (c) Sample 7, and (d) Sample 10.
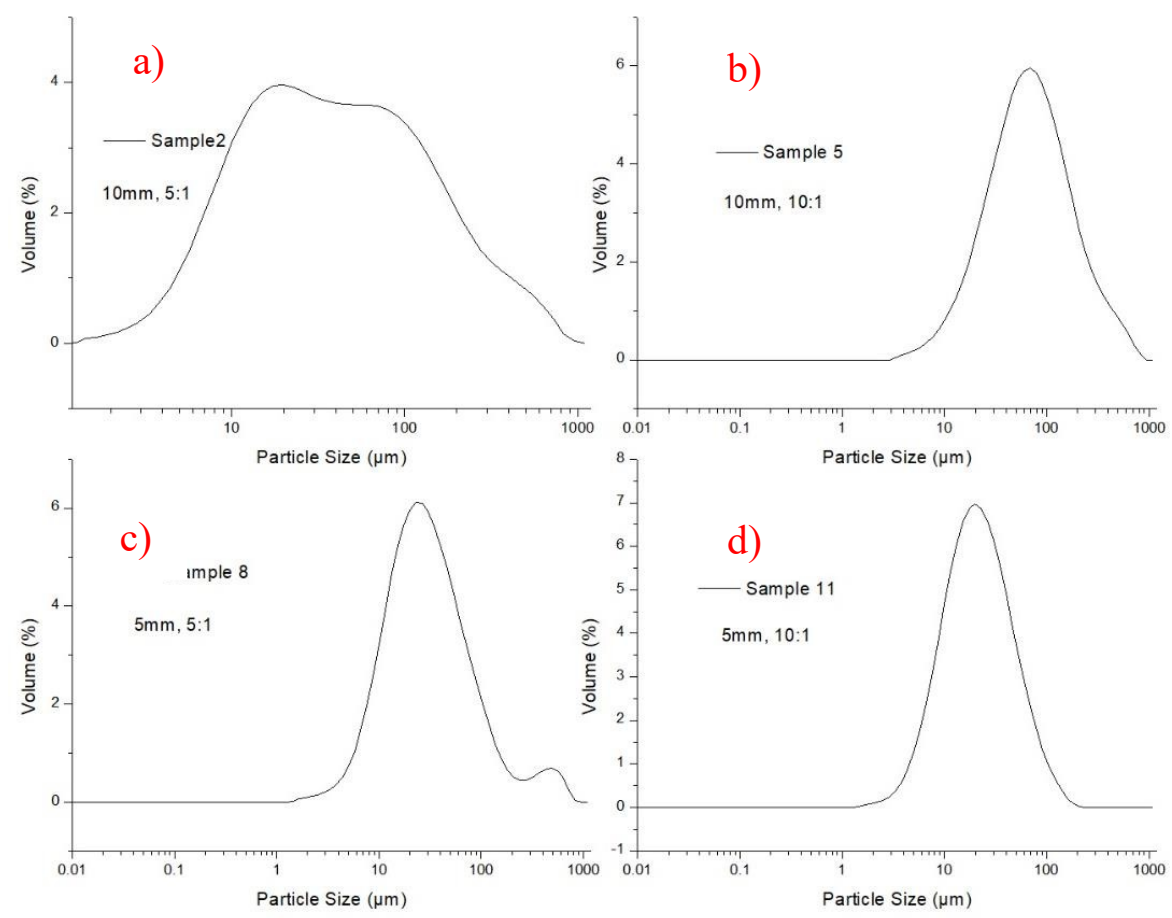

Figure 6. Evolution of PSD at $t=2 \mathrm{~h}$ for (a) Sample 2, (b) Sample 5, (c) Sample 8, and (d) Sample 11.

In the case of Figure $6 c$,d, with $5 \mathrm{~mm}$ diameter for both, but 5:1 and 10:1 BPR respectively, the trend corresponding to their $1 \mathrm{~h}$ milling times is much more evident. It is seen that all have decreased, implying that fracturing of the powders is high. Also, graphene as a reinforcement and relatively brittle phase will also aid in the fracturing process. Embedment is expected to occur during the transition of dominance of cold welding to fracture mechanism. Figure 6a refers to 
Sample 2 which was milled with balls of $10 \mathrm{~mm}$ diameter and 5:1 BPR. A significant decrease is observed in $d_{0.1}, d_{0.5}$ values from 1 to 2 . As for $\mathrm{d} 0.9$, this stayed almost the same from 1 to 2 implying that cold welding is still evident although fracturing begins to dominate. However in case of Figure $6 \mathrm{~b}$ which corresponds to Sample 5 (10 mm diameter, 10:1), it is observed that the entire particle size distribution have increased. The reason behind this could be the higher ball diameter. The high ball diameter coupled with high rotation speed of HE-MA does not give the balls both sufficient contact and time to cause fracture to the matrix phase. Hence in case of Sample 5, even after $2 \mathrm{~h}$ of milling, cold welding is still the dominant mechanism resulting in overall increase in particle sizedistribution.

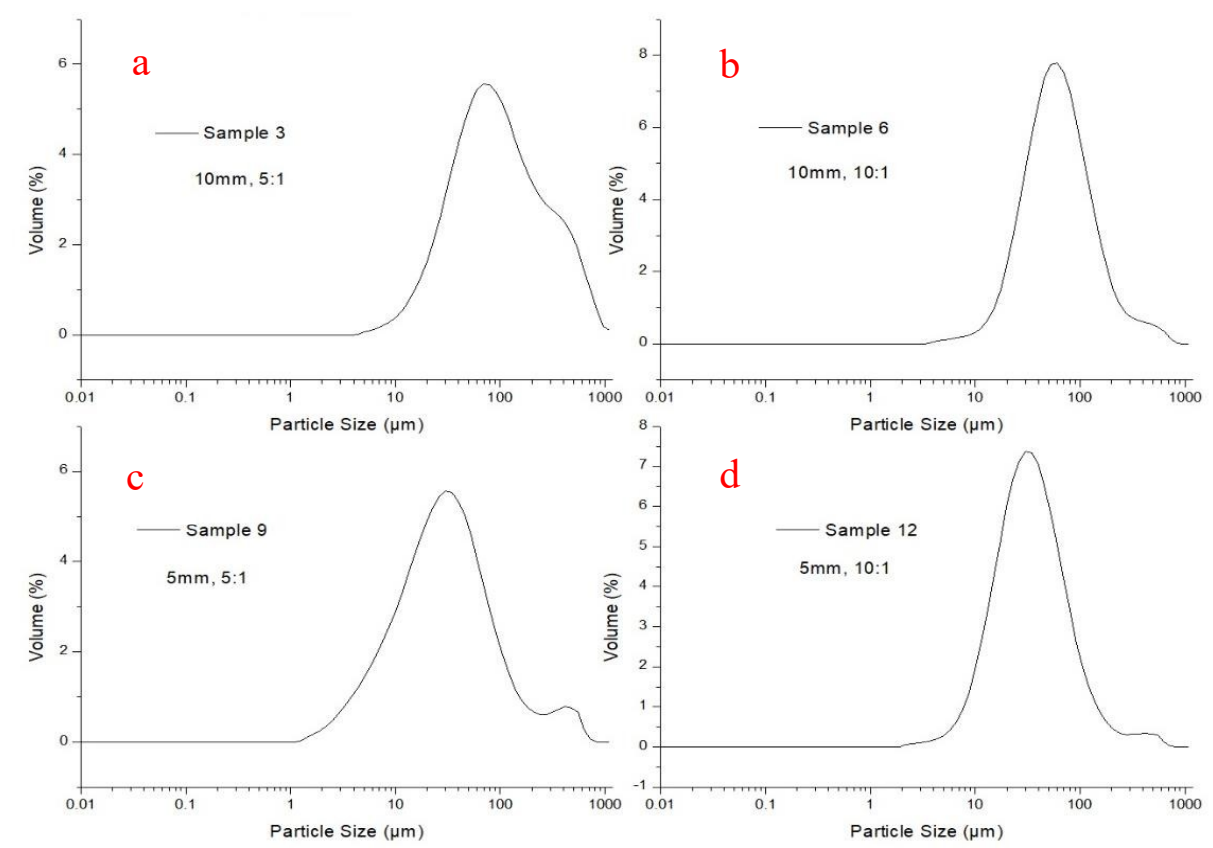

Figure 7. Evolution of PSD at $t=4 \mathrm{~h}$ for (a) Sample 3, (b) Sample 6, (c) Sample 9, and (d) Sample 12.

Figure 7 represents the powders milled for $4 \mathrm{~h}$ under different milling conditions. Figure $7 \mathrm{a}$ corresponds to Sample 3 (10 mm, 5:1 BPR). It is observed that the particle size distribution has increased considerably with respect to Sample 2 (comparing $4 \mathrm{~h}$ to $2 \mathrm{~h}$ milling of same sample). This could be due to the re-welding process that has occurred once the fracturing has reached steady state. However, observing the values of the $d_{0.1}, d_{0.5}, d_{0.9}(25.164,82.879$, and $360.869 \mu \mathrm{m}$ respectively.), this particle size distribution is not particularly favorable because of its coarse particles overall as well as wide particle distribution. The low BPR value coupled with high ball diameter have detrimental effect on the sample. Figure $7 \mathrm{c}, \mathrm{d}$ corresponds to samples milled with $5 \mathrm{~mm}$ diameter balls with BPR 5:1 and 10:1 respectively. Although their $d_{0.5}$ values $(27.03,30.77 \mu \mathrm{m}$ respectively) are quite close, deviation is observed in case of $d_{0.1}$ and $d_{0.9}$. For 5:1 BPR, $5 \mathrm{~mm}$ diameter ball milled powder (Sample 9), distribution of particles is respectively as follows $\left(d_{0.1}, d_{0.5}, d_{0.9}\right)=(6.582,27.03$, $106.885 \mu \mathrm{m}$ ). And for 10:1 BPR, 5mm diameter ball milled powder (Sample 12), distribution is respectively as follows $\left(d_{0.1}, d_{0.5}, d_{0.9}\right)=(12.034,30.776,85.954 \mu \mathrm{m})$. So Sample 12 is having better distribution than Sample 9.

\subsubsection{Effect of Ball Diameter on Particle Size}

It is clear that the smaller diameter of balls have resulted in smaller particle size for Figure 8a,b. This is in acceptance with theoretical [23] and experimental findings [24]. Shin et al.[24] found that using smaller balls will increase the number of contact points (positive factor) while at the same time small balls tend to slow down faster due to powder sedimentation during milling (negative factor). However this negative factor can be compensated if the rotation speed is high. Shin et al [24] have concluded that the higher rotation speed (rpm) results in increase in kinetic energy of 
the balls and hence smaller diameter balls are favorable in the circumstance. High Energy mechanical alloying is predominantly associated with high RPM (in this experiment, rotation speed is $1000 \mathrm{rpm}$ ) and hence it is observed that using smaller diameter balls have resulted in smaller particle size distribution.

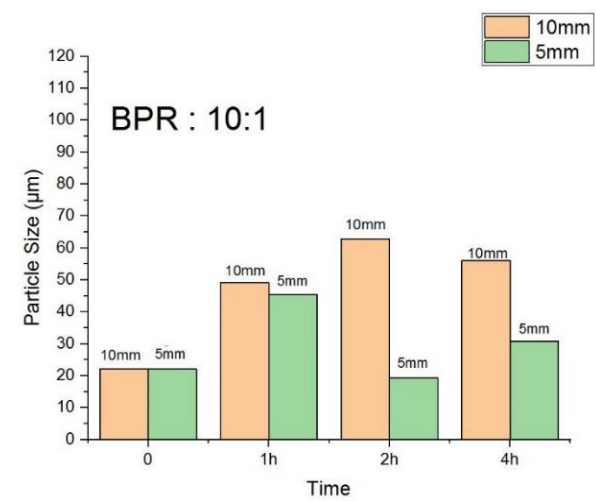

(a)

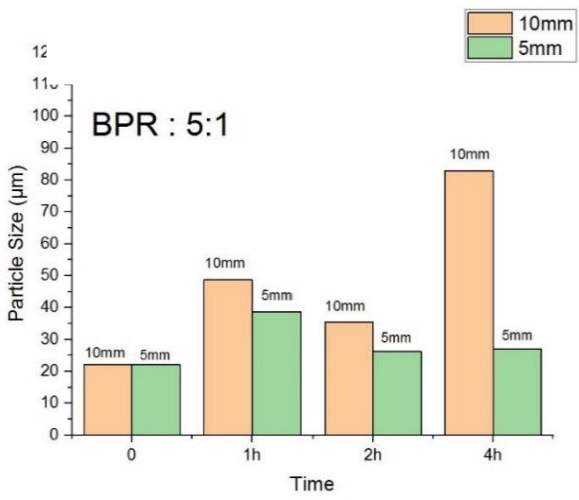

(b)

Figure 8. Effect of ball diameter on mass median diameter $\left(d_{0.5}\right)$ for (a) $B P R=10: 1$ (b) $B P R=5: 1$.

\subsubsection{Effect of BPR on Particle Size Distribution}

Higher the Ball to Powder ratio corresponds to higher weight of the balls. Hence, higher BPR implies, when the collision of balls occur, more impact is experienced by the powders on an aggregate because of higher weight of the balls. So higher BPR values have a positive effect on the HE-MA process in the long run. BPR will aid in the better distribution of force all over the powder sample resulting in better distribution of particle size in milling, with a more narrow range of particle sizes. This leads to a homogeneous powder distribution in terms of particle size. In both the cases of $10 \mathrm{~mm}$ diameter balls and $5 \mathrm{~mm}$ diameter balls, it is observed from Table 3 that better distribution of particles is achieved with 10:1 BPR. Particle size $(\mu \mathrm{m})$ is not much effected by BPR, but higher BPR leads to better particle distribution.

This section may be divided by subheadings. It should provide a concise and precise description of the experimental results, their interpretation as well as the experimental conclusions that can be drawn.

Higher the Ball to Powder ratio value implies higher weight of the balls. Hence, higher BPR implies, when the collision of balls occur, more impact is experienced by the powders on an aggregate because of higher weight of the balls. So BPR value have a positive effect on the HEMA process in the long run. BPR will aid in the better distribution of force all over the powder sample resulting in better distribution of particle size in milling with a more narrow range of particle sizes. This leads to a homogeneous powder distribution in terms of particle size.

In both the cases of $10 \mathrm{~mm}$ diameter balls and $5 \mathrm{~mm}$ diameter balls, it is observed from Table 3 that better distribution of particles is achieved with 10:1 BPR for $t=2$ and $4 \mathrm{~h}$. It can be observed from Figure 9a that after $1 \mathrm{~h}$ of milling there is no effect of BPR on powder distribution on the samples. From Figure 9b,c, for samples milled with 10:1 BPR, narrower powder distribution is observed. As the powders begins to consolidate and the milling process tends towards a steady state as the time progresses, higher BPR resulted in a better powder distribution. This can be observed in case of Sample 6 and Sample 12 from Table 3. Large chunks of particles are observed in case of Sample 1 (10 mm ball diameter with 5:1 BPR) with d0.9 value of $360.8 \mu \mathrm{m}$. Particle size $(\mu \mathrm{m})$ is not much effected by BPR, but higher BPR leads to better particle distribution.

Although desired particle size distribution is observed in case of both 2 and $4 \mathrm{~h}$ milled powders with $5 \mathrm{~mm}$ ball diameter and 10:1 BPR (Samples 11 and 12, respectively), SEM of Sample 12 reveals a more homogeneous and equiaxed microstructure which is favorable for cold spray process (see Figure 10). On the other hand, there is a large non-uniformity present in the microstructures obtained from Sample 11. 

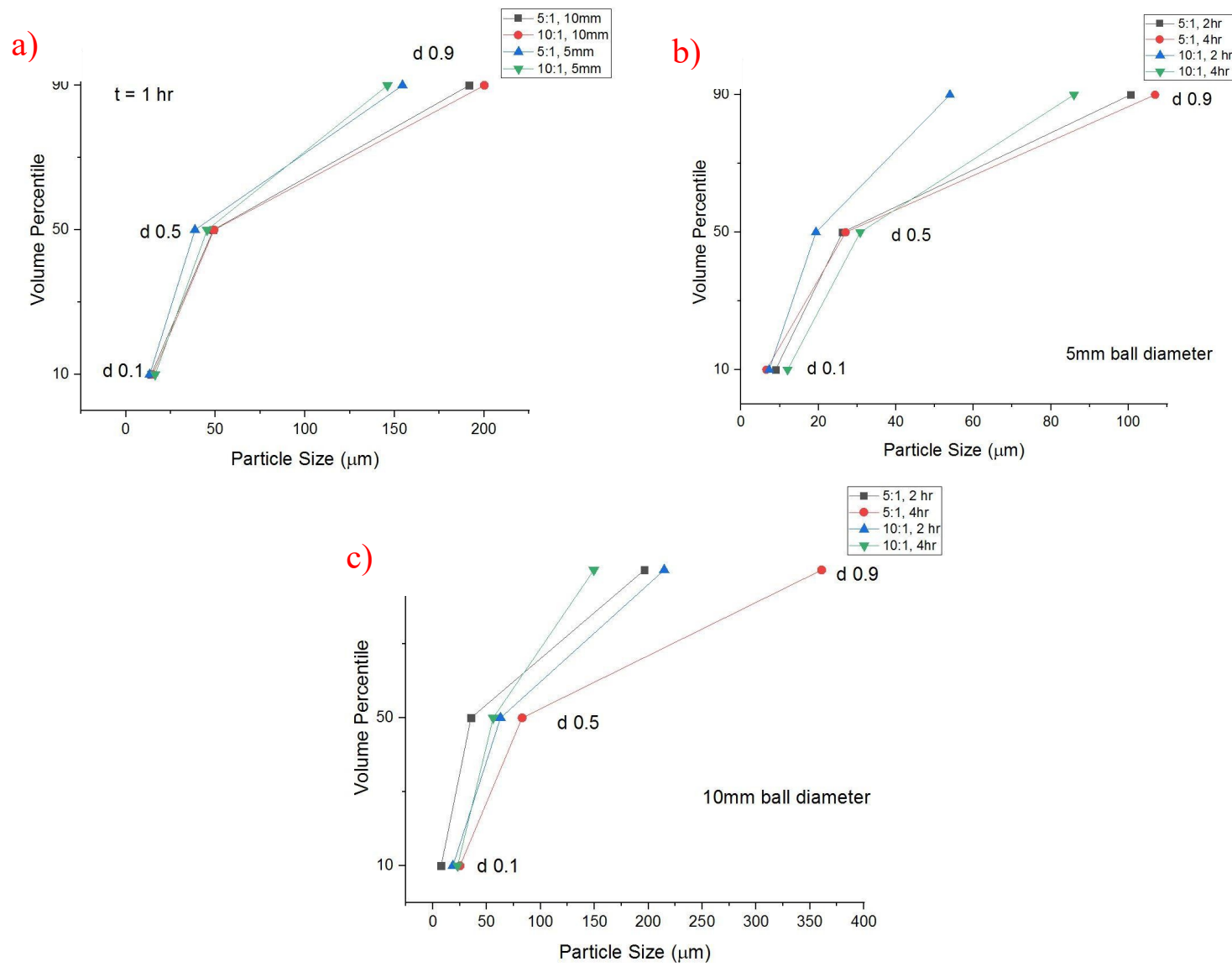

Figure 9. Effect of BPR on particle size distribution for (a) ball diameters of $5 \mathrm{~mm}, 10 \mathrm{~mm}$ after $1 \mathrm{~h}$ milling time, (b) ball diameter of $5 \mathrm{~mm}$ at after 2 and $4 \mathrm{~h}$ milling times, and (c) ball diameter of $10 \mathrm{~mm}$ at after 2 and $4 \mathrm{~h}$ milling times.
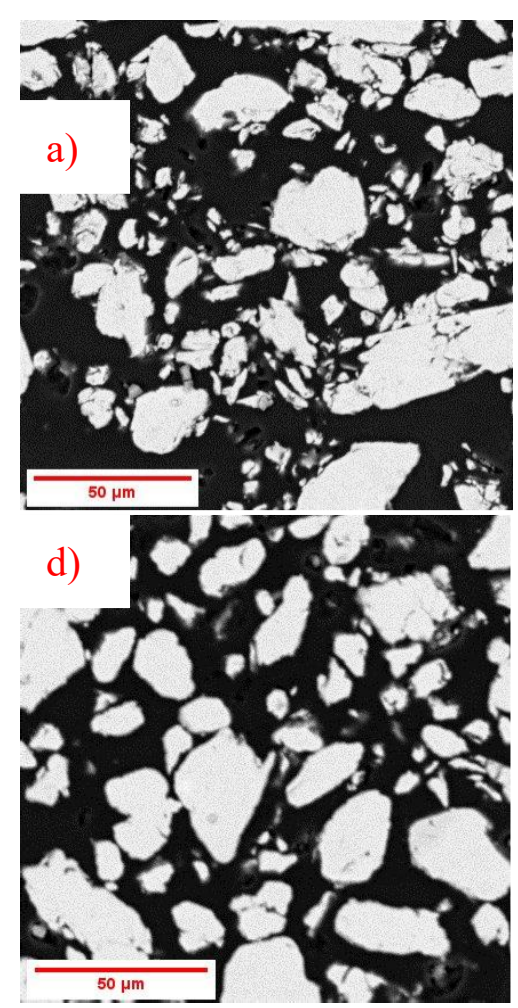

)
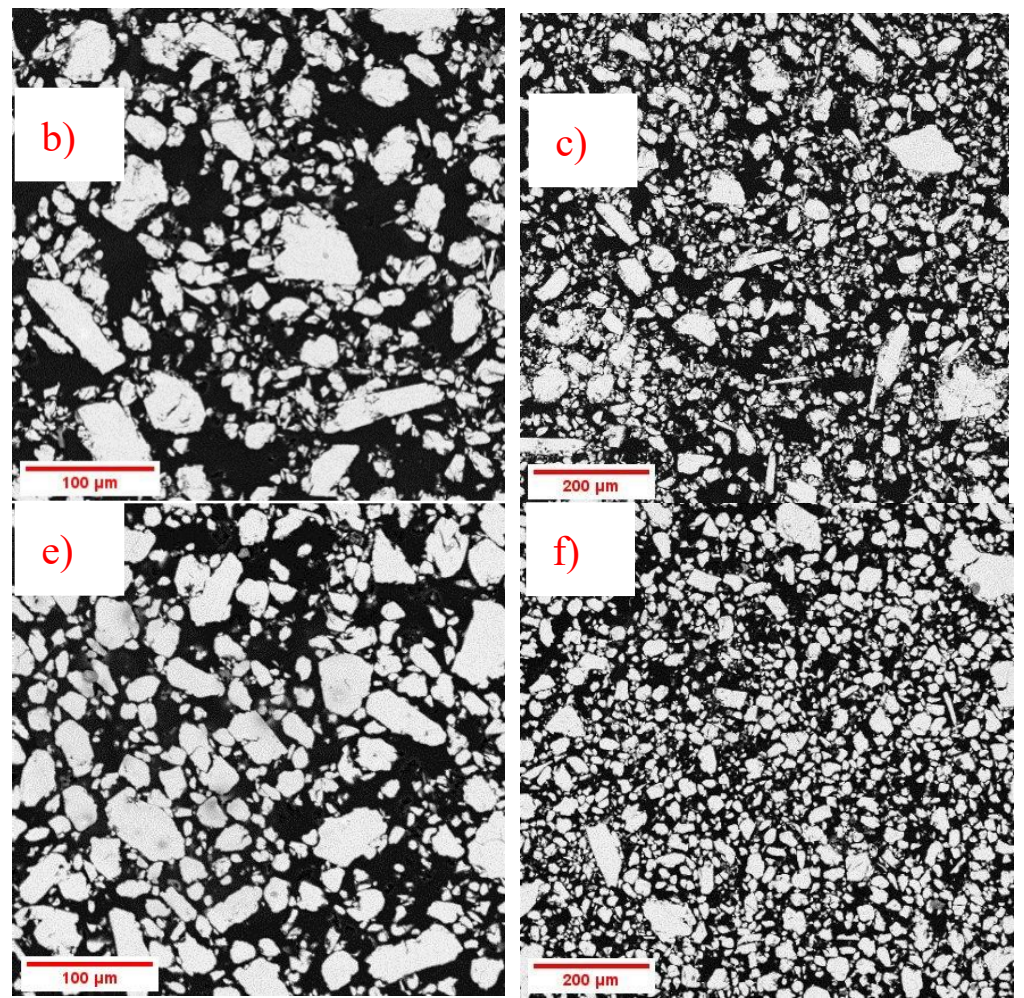

Figure 10. SEM micrographs of $(\mathbf{a}-\mathbf{c})$ Sample 11 and $(\mathbf{d}-\mathbf{f})$ Sample 12 at different magnifications. 


\section{Conclusions}

Carbon allotrope based Aluminum matrix composites are gaining vast attention because of its potential to replace existing materials in light weight applications as well as strength based applications. Synthesis of these composites will be actively pursued in diverse fields in future and although there exists various synthesis routes to manufacture these powders, High energy mechanical alloying/ball milling by far is the most economically viable and effective technique to commercially produce these composites at large scale. Also, gas dynamic cold spray or simply cold spray technique is receiving wide attention as an alternative coating process to the existing processes because of its ability to deposit coatings without melting the powder particles. Thus it will consume less energy compared to other coating processes and also prevent the problems associated with solidification of coating on substrate like splat formation, stresses etc. Among the milling parameters, BPR is observed to effect the distribution of the particles. Higher the BPR better will be the distribution of the particles. Consequently, ball diameter will affect the size range of the powder particles. For HE-MA, since the rpm is quite high, small sized diameter of the balls will help in achieving smaller sized particles. So to achieve a favorable feedstock powder, low ball diameter with high BPR is desirable with $4 \mathrm{~h}$ of milling time. However, the embedment of graphene is found to have no significant effect on the milled particle structure. To make a conclusive judgment future work is aimed at performing Raman spectroscopy, as well as high-resolution TEM.

Conflicts of Interest: The authors declare no conflict of interest

\section{References}

1. Fridlyander, N. Aluminum alloys in aircraft in the periods of 1970-2000 and 2001-2015. Met. Sci. Heat Treat. 2001, 43, 6-10. doi:10.1023/A:1010453702596.

2. Shyu, R.F.; Ho, C.T. In situ reacted titanium carbide-reinforced aluminum alloys composite. J. Mater. Process. Technol. 2006, 171, 411-416. doi:10.1016/j.jmatprotec.2004.08.034.

3. Lee, C.; Wei, X.; Kysar, J.W.; Hone, J. Measurement of the elastic properties and intrinsic strength of monolayer graphene, Science 2008, 321, 385-388. doi:10.1126/science.1157996.

4. Zhu, Y.; Murali, S.; Cai, W.; Li, X.; Suk, J.W.; Potts, J.R.; Ruoff, R.S. Graphene and graphene oxide: synthesis, properties, and applications. Adv. Mater. 2010, 22, 3906-3924. doi:10.1002/adma.201001068

5. Alkhimov, A.P.; Papyrin, A.N.; Dosarev, V.F.; Nesterovich, N.I.; Shuspanov, M.M. Gas Dynamic Spraying Method for Applying a Coating. U.S. Patent 5,302,414, 12 April 1994.

6. Tokarev, A.O. Structure of aluminum powder coatings prepared by cold gas dynamic spraying. Met. Sci. Heat Treat. 1996, 38, 136-139. doi:10.1007/BF01401446.

7. Moridi, A.; Hassani-Gangaraj, S.M.; Guagliano, M.; Dao, M. Cold spray coating: review of material systems and future perspectives. Surf. Eng. 2014, 30, 369-395. doi:10.1179/1743294414Y.0000000270.

8. Al-Hamdani, K.S.; Murray, J.W.; Hussain, T.; Kennedy, A.; Clarea, A.T. Cold sprayed metal-ceramic coatings using satellited powders. Mater. Lett. 2017, 198, 184-187. doi:10.1016/j.matlet.2017.03.175.

9. Li, W.; Assadi, H.; Gaertner, F.; Yin, S. A review of advanced composite and nanostructured coatings by solid-state cold spraying process. Crit. Rev. Solid State Mater. Sci. 2018. doi:10.1080/10408436.2017.1410778.

10. Pathak, S.; Saha, G.C. Development of sustainable cold spray coatings and 3D additive manufacturing components for repair/manufacturing applications: a critical review. Coatings 2017, 7, 122.

11. Tang, J.; Saha, G.C.; Richter, P.; Kondás, J.; Colella, A.; Matteazzi, P. Effects of post-spray heat treatment on hardness and wear properties of Ti-WC high-pressure cold spray coatings. J. Therm. Spray Technol. 2018, 27, 1153-1164. doi:10.1007/s11666-018-0762-7.

12. Helfritch, D.; Champagne, V. A model study of powder particle size effects in cold spray deposition. In Proceedings of the 26th Army Science Conference, Orlando, FL, USA, 1-4 December 2008.

13. Yin, S.; Chen, C.; Suo, X.; Lupoi, R. Cold-sprayed metal coatings with nanostructure. Adv. Mater. Sci. Eng. 2018, 2018, 2804576. doi:10.1155/2018/2804576.

14. Nath, L.; Saha, G.C. Synthesis and characterization of nanocrystalline $\mathrm{Al}_{2} \mathrm{O}_{3}-\mathrm{Ni}(\mathrm{Cr})$ particles using highenergy mechanical alloying process. Surf. Coat. Technol. 2017, 318, 262-269.

15. Nath, L.; Saha, G.C.; Brüning, R. Nanocrystalline $\mathrm{Al}_{2} \mathrm{O}_{3}-\mathrm{Ni}(\mathrm{Cr})$ particle synthesis by high-energy mechanical alloying method. J. Alloy. Compd. 2018, 758, 224-236. doi:10.1016/j.jallcom.2018.05.114. 
16. Zhang, J.; Chen, Z.; Zhao, J.; Jiang, Z. Microstructure and mechanical properties of aluminum-graphene composite powders produced by mechanical milling. Mech. Adv. Mater. Modern Process. 2018, 4, 4. doi:10.1186/s40759-018-0037-5.

17. Bartolucci, S.F.; Paras, J.; Rafiee, M.A.; Rafiee, J.; Lee, S.; Kapoor, D.; Koratkar, N. Graphene-aluminum nanocomposites. Mater. Sci. Eng. A 2011, 528, 7933-7937. doi:10.1016/j.msea.2011.07.043.

18. Hu, Z.; Tong, G.; Lin, D.; Chen, C.; Guo, H.; Xu, J.; Zhou, L. Graphene-reinforced metal matrix nanocomposites: A review. Mater. Sci. Technol. 2016, 32, 930-953. doi:10.1080/02670836.2015.1104018.

19. Nieto, A.; Bisht, A.; Lahiri, D.; Zhang, C.; Agarwal, A. Graphene reinforced metal and ceramic matrix composites: A review. Int. Mater. Rev. 2017, 62, 241-302. doi:10.1080/09506608.2016.1219481.

20. Suryanarayana, C.; Al-Aqeeli, N. Mechanically alloyed nanocomposites. Prog. Mater. Sci. 2013, 58, 383502. doi:10.1016/j.pmatsci.2012.10.001.

21. Gupta, R.K.; Murty, B.S.; Birbilis, N.; High-energy ball milling parameters in production of nanocrystalline Al alloys. In An Overview of High-Energy Ball Milled Nanocrystalline Aluminum Alloys, 1st ed.; Gupta, R.K., Murty, B.S., Birbilis, N., Eds.; Springer International Publishing: New York, NJ, USA, 2017; pp. 8-20.

22. Toozandehjani, M.; Matori, K.A.; Ostovan, F.; Aziz, S.A., Mamat, M.S. Effect of milling time on the microstructure, physical and mechanical properties of $\mathrm{Al}_{-} \mathrm{Al}_{2} \mathrm{O}_{3}$ nanocomposite synthesized by ball milling and powder metallurgy. Materials 2017, 10, 1232. doi:10.3390/ma10111232.

23. Austin, L.G.; Shoji, K.; Luckie, P.T. The Effect of ball size on mill performance. Powder Technol. 1976, 14, 7179. doi:10.1016/0032-5910(76)80009-5.

24. Shin, H.; Lee, S.; Jung, H.S.; Kim, J-B. Effect of ball size and powder loading on the milling efficiency of a laboratory-scale wet ball mill. Ceram. Int. 2013, 39, 8963-8968. doi:10.1016/j.ceramint.2013.04.093.

(C) 2019 by the authors. Licensee MDPI, Basel, Switzerland. This article is an open access article distributed under the terms and conditions of the Creative Commons Attribution (CC BY) license (http://creativecommons.org/licenses/by/4.0/). 